\title{
Final Analysis Output
}

National Cancer Institute

\section{Source}

National Cancer Institute. Final Analysis Output. NCI Thesaurus. Code C115554.

The information and data generated from a final analysis dataset of a clinical trial. 